www.jmscr.igmpublication.org

Index Copernicus Value: 79.54

ISSN (e)-2347-176x ISSN (p) 2455-0450

crossref DOI: https://dx.doi.org/10.18535/jmscr/v7i4.91

Journal Of Medical Science And Clinical Research

IGM Publication

An Official Publication of IGM Publication

\title{
A Comparative Study of Palliative Hypofractionated vs Conventional Fractionated Radiotherapy in Locally Advanced non Small Cell Lung Cancer
}

Authors

\author{
Dr Guman Singh ${ }^{1}$, Dr Saroj Dhaka ${ }^{2 *}$, Dr Neeti Sharma ${ }^{3}$, Dr H.S.Kumar ${ }^{4}$
}

${ }^{1}$ Assistant Professor, Radiation Oncology Department, M.G. Medical College, Jaipur

${ }^{2}$ Resident Doctor, Radiation Oncology Department, ATRCTRI, S.P. Medical College, Bikaner

${ }^{3}$ Professor, Radiation Oncology Department, ATRCTRI, S.P. Medical College, Bikaner

${ }^{4}$ Senior Professor and Head, Radiation Oncology Department, ATRCTRI, S.P. Medical College, Bikaner

*Corresponding Author

Dr Saroj Dhaka

Resident Doctor, Radiation Oncology Department, ATRCTRI, S.P. Medical College, Bikaner, India

\begin{abstract}
Purpose: To compare the compliance, tumor response, quality of life and survival between a hypofractionated \& a conventional fractionated RT schedule in locally advanced NSCLC patients.

Materials \& Methods: Total 50 patients with unresectable stage III NSCLC were given 3 cycle of neoadjuvant chemotherapy. After 3-4 weeks of completion of $3^{\text {rd }}$ cycle, 25 patients received a total 17Gy in $2 \mathrm{fr}(8.5 \mathrm{~Gy} / \mathrm{fr})$ on dayl \& day8 in study arm, 25 patients received a total $50 \mathrm{~Gy}$ in $25 \mathrm{fr}(2 \mathrm{~Gy} / \mathrm{fr})$ administered daily(5days/week) for 5 weeks. Disease response was evaluated by RECIST criteria at 1, 3 \&6 month. Then follow up was done after $1 y r, 2 y r \& 3 y r$ to evaluate the overall survival.

Result: none of patients in both arms had complete response at any follow up. Locoregional disease contol was observed in $18 \%$ \& $27 \%$ in study \& control arm respectively ( $p$ value >0.05). Median survival was 10 months \& 12.5 months in study \& control arm respectively which was not statistically significant. There was no statistically difference in grade of toxicities. OS rates at 1, 2\& 3years were 40\%, 10\% \&0\% in study arm and 50\%, 20\% \&5\% in control arm but difference in OS was not statistically significant.

Conclusion: Many patients were lost to follow up in our study; although among the patients followed, we found to concluded that for improvement of quality of life in locally advanced NSCLC patients with poor $P S \&$ short life span, the palliative hypofractionated regimen of short duration (17Gy/2fr) could be considered as a reasonable alternative and also economically feasible \& required shorter duration of stay in the hospital. In conclusion, large number of patients with strict follow up need to be done to ascertain the need and benefits of this palliative TRT.

Keyword: Unresectable stage III non small cell lung cancer, conventional radiation, hypofractionated radiation, neoadjuvant $C T$.
\end{abstract}

\section{Introduction}

Worldwide lung cancer is the most common and deadliest form of cancer accounting for $13 \%$ of all new cancer cases and 19\% of cancer related deaths worldwide ${ }^{1}$. Among males lung cancer is the most commonly diagnosed cancer and leading 
cause of cancer death ${ }^{2}$. Among females, it is the $4^{\text {th }}$ most commonly diagnosed cancer (after breast, oral, colorectal and cervical cancer)and second leading cause of cancer death $\left(1^{\text {st }}\right.$ being breast cancer $)^{3}$. In india, currently lung cancer is the $4^{\text {th }}$ largest cause of cancer, accounting for nearly $8 \%$ of all cancer related deaths in the country. At diagnosis, nearly $70 \%$ of patients present with locally advanced or metastatic disease ${ }^{4}$. About 55\% patients with NSCLC present advanced lung cancer are treated with palliative intent. In advanced stage patients of NSCLC the performance status is used to estimate a patient's prognosis, tolerance and potential benefits of chemotherapy .Vast majority of patients are incurable at presentation and majority of them will die from their locoregional disease. Most of patients develop thoracic symptoms during their illness. The goal of providing effective palliation while avoiding unacceptable toxicity should be incorporated while choosing treatment modality. The overall survival rate of lung cancer is $23 \%$ and $10 \%$ with stage IIIA and IIIB, IV respectively. The median survival is roughly 13 months with treatment. The rationale behind the sequential chemo-radiotherapy is based on that RT addresses locoregional control whereas $\mathrm{CT}$ acts systemically to eradicate micro-metastasis ${ }^{6}$.

Hypofrationation refers to administration of radiotherapy utilizing a small number of fractions with a larger dose per fraction. Invitro experiments indicated that the dose needed to kill severely hypoxic cells is on the order of 2 or 3 time the dose needed for oxic cells. Therefore, delivering a higher RT dose to tumour may result in higher tumour cell kill and improved local control. One approach to increase RT dose is to use hypo-fractionated RT, which not only increases the dose, but also reduces the overall treatment time.

This study is intended to evaluate the benefits of hypofractionated RT in advanced stage lung cancer patients previously treated with induction chemotherapy in favour of symptom control, quality of life, toxicity profile, median and overall survival.

\section{Materials and Methods}

This was a randomised prospective study conducted at Acharya Tulsi Regional Cancer Treatment And Research Institute, Sardar Patel Medical College and associated group of hospital, Bikaner.

The study protocol include 50 patients of locally advanced NSCLC patients of stage IIIA-IIIB, histologically proven cases of non small cell carcinoma, who were inrolled from july 2012 to july 2013. Inclusion criteria included inoperable, locally advanced, histologically proved, stage IIIA\&IIIB NSCLC patients, ECOG performance status 2-3, tumor related chest symptoms (cough, dyspnea, haemoptysis, chest pain, dysphagia), age up to 75 years, without any haematological, cardiac, renal or liver function abnormality, no previous history of treatment for the lung cancer and no any other concurrent malignancy.

All 50 patients were randomly selected in two arms of 25 patients in each. The both arms were treated by sequential chemo-radiotherapy. Neoadjuvant chemotherapy was 3 cycle, each consisting of inj cisplatin $40 \mathrm{mg} / \mathrm{m}^{2}$ on day $1 \& 2$ and inj paclitaxel $175 \mathrm{mg} / \mathrm{m}^{2}$ on day 1 .

Radiotherapy was planned after 3-4 weeks from last cycle of chemotherapy. In study arm, patients received a total $17 \mathrm{~Gy}$ in 2 fractions $(8.5 \mathrm{~Gy}$ for each fraction) on day $1 \&$ day 8 (Hypofractionated radiotherapy) and control arm, patients received a total 50 Gy in 25 fractions (2 Gy for each fraction), administered daily (5 days per week) for 5 weeks (conventional fractionated radiotherapy).

Treatment volume were included primary tumor site plus mediastinum region. Parallel opposed antero-posterior fields were planned. The dose was priscribed at midline. External beam radiotherapy was given with radiation therapy parameter on cobalt-60 machines Theratron 780E/ $780 \mathrm{C} /$ Bhabhatron II with photon energies of 1.25MeV. Minimum treatment distance was $>=80$ $\mathrm{cm}$ SSD. Patients were under monitoring after 
every course of chemotherapy and prior to \& during radiotherapy. In each monitoring, patients were assessed for treatment response, control of symptoms and any treatment related morbidity by doing complete blood counts, biochemistry profile consisting of RFT\&LFT, chest X-ray, USG Abdomen. Toxicity haematological, renal, biochemical, skin reactions and disease response were assessed. After 1 month of completion of radiotherapy patients were called for first follow up visit and were assessed for treatment response and palliation of symptoms. On first follow up visit complete general-physical examination, haemogram, RFT, Chest X-ray \&CECT Thorax were done for treatment response \&toxicity evaluation and metastic workup were consist of USG Abdomen and LFT.

On subsequent follow up in $3^{\text {rd }}, 6^{\text {th }}$ month, detailed systemic examination, CBC, LFT, RFT, chest x-ray and USG Abdomen was done to evaluate for distant metastasis and complications RT like mediastinitis, esophagitis and radiation pneumonitis. The result of both arms were analysed \& compared in terms of various aspects like quality of life, tumor response and symptom relief.

\section{Results}

Table 1 Patients characteristics

\begin{tabular}{|l|c|c|}
\hline Patients characterstics & Study Arm & Control Arm \\
\hline Age (in years ) & & \\
\hline Median age & $59 \mathrm{yr}$ & $59 \mathrm{yr}$ \\
range & $48-75 \mathrm{yrs}$ & $40-75 \mathrm{yrs}$ \\
\hline Sex (\%) & & \\
\hline Male & $1 \%$ & $92 \%$ \\
Female & & $2 \%$ \\
\hline Weight & $59 \mathrm{~kg}$ & \\
\hline Median & $46-68 \mathrm{~kg}$ & $45-68 \mathrm{~kg}$ \\
Range & & \\
\hline ECOG (\%) & $28 \%$ & $40 \%$ \\
\hline 2 & $72 \%$ & $60 \%$ \\
3 & & \\
\hline Tumor stage(\%) & $8 \%$ & $12 \%$ \\
\hline $\mathrm{T}_{2}$ & $36 \%$ & $52 \%$ \\
$\mathrm{~T}_{3}$ & $56 \%$ & $36 \%$ \\
$\mathrm{~T}_{4}$ & & \\
\hline $\mathrm{N}_{4}$ (al stage( \%) & $4 \%$ & $0 \%$ \\
\hline $\mathrm{N}_{0}$ & $8 \%$ & $24 \%$ \\
$\mathrm{~N}_{1}$ & $68 \%$ & $60 \%$ \\
$\mathrm{~N}_{2}$ & $20 \%$ & $16 \%$ \\
$\mathrm{~N}_{3}$ & & \\
\hline Group stage (\%) & $54 \%$ & $52 \%$ \\
\hline Stage IIIA & $56 \%$ & $48 \%$ \\
Stage IIIB & & \\
\hline
\end{tabular}

Table 2: Treatment response

\begin{tabular}{|l|c|c|}
\hline \multirow{2}{*}{$\begin{array}{l}\text { Treatment } \\
\text { response }\end{array}$} & \multicolumn{2}{|c|}{ Number of patients } \\
\cline { 2 - 3 } & $\begin{array}{c}\text { Study arm (22) } \\
100 \%\end{array}$ & $\begin{array}{c}\text { Control arm (22) } \\
100 \%\end{array}$ \\
\hline Regressive disease & $4(18 \%)$ & $6(27 \%)$ \\
\hline Stable disease & $5(23 \%)$ & $7(32 \%)$ \\
\hline Progressive disease & $13(59 \%)$ & $9(41 \%)$ \\
\hline
\end{tabular}

\section{Column1}

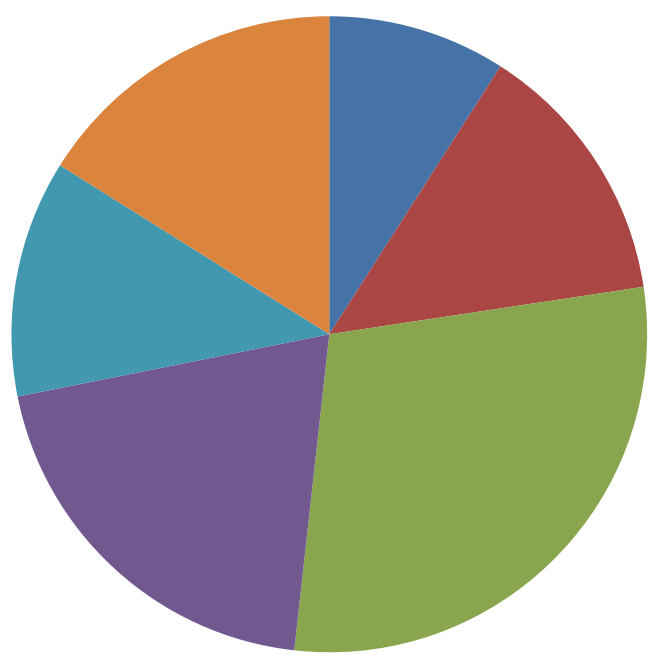

- regressive disease study

regressive disease control

progressive disease study

- progressive disease control

- stable disease study

$\square$ stable disease control 
Table 3: Relief of symptoms

\begin{tabular}{|l|c|c|c|c|c|c|c|}
\hline Symptoms & Arm & Baseline & After CT3 & $\begin{array}{c}\text { At end of } \\
\text { treatment }\end{array}$ & Ist month & $3^{\text {rd }}$ month & $6^{\text {th }}$ month \\
\hline Chest pain & Study & $17(77.27 \%)$ & $13(59.09 \%)$ & $8(36.36 \%)$ & $5(22.73 \%)$ & $6(27.27 \%)$ & $11(50 \%)$ \\
\cline { 2 - 8 } & Control & $15(68.18 \%)$ & $11(50 \%)$ & $5(22.72 \%)$ & $3(13.63 \%)$ & $3(13.63 \%)$ & $7(31.18 \%)$ \\
\hline \multirow{2}{*}{ Dyspnoea } & Study & $18(81.81 \%)$ & $14(63.63 \%)$ & $9(40.90 \%)$ & $7(31.18 \%)$ & $7(31.18 \%)$ & $13(59.09 \%)$ \\
\cline { 2 - 8 } & Control & $15(68.18 \%)$ & $12(54.54 \%)$ & $7(31.18 \%)$ & $4(18.18 \%)$ & $5(22.72 \%)$ & $9(40.90 \%)$ \\
\hline Cough & Study & $16(72.72 \%)$ & $12(54.54 \%)$ & $8(36.36 \%)$ & $6(27.27 \%)$ & $7(31.18 \%)$ & $12(54.54 \%)$ \\
\cline { 2 - 8 } & Control & $19(86.36 \%)$ & $15(68.18 \%)$ & $9(40.90 \%)$ & $6(27.27 \%)$ & $6(27.27 \%)$ & $10(45.45 \%)$ \\
\hline \multirow{2}{*}{ Haemoptysis } & Study & $8(36.36 \%)$ & $4(18.18 \%)$ & $1(4.54 \%)$ & $1(4.54 \%)$ & $2(9.09 \%)$ & $4(18.18 \%)$ \\
\cline { 2 - 8 } & Control & $6(27.27 \%)$ & $3(13.63 \%)$ & $1(4.54 \%)$ & $1(4.54 \%)$ & $1(4.54 \%)$ & $2(9.09 \%)$ \\
\hline
\end{tabular}

Most of patients had ECOG performance status 3, median age $59 \mathrm{yr}$, male gender, median weight $59 \mathrm{~kg} \&$ stage IIIA\&IIIB in both arms. During the treatment $2 \& 3$ patients lost from follow up in arm A\& arm $\mathrm{B}$ respectively. While 1 patient expired after receiving 3 cycle of chemotherapy.

At $6^{\text {th }}$ month follow up- None of patients had complete response in study \& control arm for any stage $\left(X^{2}=0, p=1\right) 4 \& 6$ patients had regression $\left(\mathrm{x}^{2}=1.818, \mathrm{p}=0.177\right) 5 \& 7$ patients had stable disease $\left(x^{2}=1.515, p=0.218\right)$ and $13 \& 9$ patients had progression of disease $\left(x^{2}=3.309, p=0.068\right)$ in study \& control arm respectively. When analyzed at $6^{\text {th }}$ month follow up, $82 \% \& 73 \%$ patients had progressive/stable disease in study and control arm respectively while $18 \%$ patients in study \& $27 \%$ patients in control arm had regression of disease.

Overall survival rates at 1,2 and 3 years were $40 \%, 10 \%$ \& $0 \%$ in study arm while in control arm those values were $50 \%, 20 \%$ \& $5 \%$ respectively. But on statistical analysis those difference in overall survival were not significant ( $p$ value were $0.4,0.7 \& 1.5$ for $1,2 \& 3$ year OS respectively). Range of survival were 7 to 25 months in study arm and 10 to 48 months in control arm. Median survival were10 months and 12.5 months in study and control arm respectively. The palliation of symptoms was slightly better \& was for longer duration in control arm, though early palliation was achieved in study arm. It was observed that in patients with good PS, palliation achieved was better.

\section{Discussion}

The present study was carried out to identify possible prognostic indicators by assessing health related quality of life (HRQOL). With regard to treatment effect on disease related symptoms in advanced NSCLC, hypofractionated palliative RT is equivalent to conventional higher dose RT. Even though the treatment is palliative, there is limited potential for long term survival in localized disease. In the present study, which was restricted to stage IIIA \& IIIB patients considered not suitable for curative radical RT, some long term survivors were observed in the higher dose treatment arm. The most common symptoms that are considered for palliative thoracic RT include dyspnoea, cough, haemoptysis and chest pain. The symptoms occur as a result of tumor related obstruction and irritation of normal intra thoracic structures.

Sundstrom $S$ et al. study evaluating three treatment arms $17 \mathrm{~Gy} / 2 \mathrm{fr}, 42 \mathrm{~Gy} / 15 \mathrm{fr}$ and $50 \mathrm{~Gy} / 25 \mathrm{fr}$ concluded that protracted palliative TRT renders no improvement in symptom relief, HRQOL or survival when compared with short term hypofractionated treatment in NSCLC patient with disease too advanced for curative RT. Symptom relief and HRQOL were equivalent in all treatment arms. No significant difference in survival among arms was found.

In our study, symptom free survival was slightly better and for longer duration in control arm, though early palliation was achieved in study arm. It was observed that in patient with good performance status palliation achieved was better. For symptomatic patients with poor PS, stage IIIB disease too advanced for curative RT, palliative 
RT is recommended. The fractionation pattern should be chosen on the basis of the patient's need. Patients with vigorous disease may be treated with a longer RT schedule to palliate symptoms for longer period and to increase survival. But patients with very tenuous health \& very short estimated survival should be treated with a short course of RT to palliate their symptoms without using up a great amount of their limited life.

Our toxicity data support that cough, dysphagia, dyspnoea, nausea/vomiting \&anorexia were most common toxicities reported by study population. Although all the treatment toxicities (except dysphagia which which was more in study arm) were in control arm, the difference in toxicities in both arms were not statistically significant.

Improvement in chest pain and haemoptysis were comparable in both arms except that it showed early improvement in study arm but maintained only for shorter duration in study arm compared to control arm.

\section{Conclusion}

Many patients were lost to follow up in our study; although among the patients followed, we found to concluded that for improvement of quality of life in locally advanced NSCLC patients with poor PS \& short life span, the palliative hypofractionated regimen of short duration $(17 \mathrm{~Gy} / 2 \mathrm{fr})$ could be considered as a reasonable alternative and also economically feasible \& required shorter duration of stay in the hospital. In conclusion, large number of patients with strict follow up need to be done to ascertain the need and benefits of this palliative TRT.

\section{References}

1. GLOBOCAN 2012(IARC) section of cancer information database, International Agency for Research on Cancer, World Health Organization. Available at http://wwwdep.iarc.fr/, last accessed January 12, 2014 Globocan.iarc.fr/pages/fact_sheet_populatio n. aspx? country=356
2. Kaneko S, Ishikawa KB, Yoshimi I, et al. Projection of Lung cancer mortality in Japan. Cancer Sci 2003;94(10):919.

3. K. Park. Park's Textbook of Preventive and Social Medicine, 21st edition.chapter no.6Epidemiology of chronic non communicable disease and conditions. Page no. 353-54.

4. Perez C, Pajak T, Rubin P, et al. Long-term observations of the patterns of failure in patients with unresectable non-oat cell carcinoma of the Lung treated with definitive radiotherapy. Report by the Radiation Therapy Oncology Group. Cancer 1987;59:1874-1881.

5. https://www.cancer.org/cancer/non-smallcell-lung-cancer/treating/by-stage.html

6. https://www.sciencedirect.com/topics/medic ine-and-dentistry/induction-chemotherapy

7. http://ozradonc.wikidot.com/alteredfractionation

8. Ml Saunders', A Rojas2, BE Lyn', K Pigott', M Powell', K Goodchild', PJ Hoskin', H Phillips' and $\mathrm{N}$ Verma. Experience with dose escalation using CHARTWEL (continuous hyperfracti-onated accelerated radiotherapy weekend less) in non-smallcell lung cancer. British Journal of Cancer 1 998; 7841 0: 1 323-1328.

9. Jindal SK, Malik SK, Datta BN; Lung cancer in Northern India in relation to age, sex and smoking habits. Eur J Respir Dis, 1987. Jan;70(1):23-28.

10. Curran W, Scott C, Langer C, et al. Longterm benefit is observed in a phase III comparison of sequential vs. concurrent chemo-radiation for patients with unresected stage III nonsmall-cell lung cancer: Pro Am Soc Clin Oncol 2003;22:621.

11. Rolland E, LE Chevalier T, Auperin A et al. sequential radio-chemotherapy vs concurrent radio-chemotherapy vs radiotherapy alone in Locally Advanced NSCLC; Two meta-analysis using Individual Patients Data(IPD) from 
randomized clinical trials(RCTs). J Thorac Oncol (2007);2(8):s309-s310.

12. Auperin A, Le Pechoux C, Rolland E, et al. Meta-analysis of CCRT verses sequential radiochemotherap in locally advanced nonsmall-cell lung cancer. J Clin Oncol 2010;28:2181-90.

13. Curran WJ Jr1, Paulus R, Langer CJ, Komaki R, Lee JS, Hauser S, Movsas B, Wasserman T, Rosenthal SA, Gore E, Machtay M, Sause W, Cox JD. Sequential vs. concurrent chemoradiation for stage III non-small cell lung cancer: randomized phase III trial RTOG 9410. J Natl Cancer Inst. 2011 Oct 5;103(19):1452-60. doi: 10.1093/jnci/djr325. Epub 2011 Sep 8.

14. Fournel P1, Robinet G, Thomas P, Souquet PJ, Léna H, Vergnenégre A, Delhoume JY, Le Treut J, Silvani JA, Dansin E, Bozonnat MC, Daurés JP, Mornex F, Pérol M; Groupe Lyon-Saint-Etienne d'Oncologie Thoracique-Groupe Français de PneumoCancérologie. Randomized phase III trial of sequential chemoradiotherapy compared with concurrent chemoradiotherapy in locally advanced non-small-cell lung cancer: Groupe Lyon-Saint-Etienne d'Oncologie Thoracique-Groupe Français de Pneumo-Cancérologie NPC 95-01 Study. J Clin Oncol. 2005 Sep 1;23(25):5910-7. Epub 2005 Aug 8.

15. Aupérin A1, Le Péchoux C, Rolland E, Curran WJ, Furuse K, Fournel P, Belderbos J, Clamon G, Ulutin HC, Paulus R, Yamanaka T, Bozonnat MC, Uitterhoeve A, Wang X, Stewart L, Arriagada R, Burdett S, Pignon JP. Meta-analysis of concomitant versus sequential radiochemotherapy in locally advanced non-small-cell lung cancer. J Clin Oncol. 2010 May 1;28(13):2181-90. doi: 10.1200/JCO.2009.26.2543. Epub 2010 Mar 29.
16. Dillman R, Seagren S, Propert K, et al. A randomized trial of induction chemotherapy plus high-dose radiation versus radiation alone in stage III non-small-cell lung cancer. N Engl J Med 1990; 323:940-945.

17. Vokes EE, Herndon JE 2nd, Kelley MJ, Cicchetti MG, Ramnath N, et al. induction chemotherapy followed by chemoradiotherapy compared with chemoradiotherapy alone for regionally advanced unresectable stage III Non-small-cell lung cancer: Cancer and Leukemia Group B. J Clin Oncol2007;25:1698-704.

18. Belani CP, Choy H, Bonomi P, et al. Combined chemoradiotherapy regimens of paclitaxel and carboplatin for locally advanced non-small-cell lung cancer: a randomized phase II locally advanced multimodality protocol. J Clin Oncol 2005;23:5883-5891.

19. Hotta, K., et al., Addition of platinum compounds to a new agent in patients with advanced non-small-cell lung cancer: a literature based meta-analysis of randomised trials. Ann Oncol, 2004. 15(12): p. 1782-9.

20. Saunders M, Dische S, Barrett A, et al. Continuous, hyperfractionated, accelerated radiotherapy (CHART) versus conventional radiotherapy in non-small cell Lung cancer: mature data from the randomised multicentre trial. Radiother Oncol 1999;52:137-148.

21. M.I. Saunders, A. Rojasf1,B.E. Lyn,E. Wilson, H. Phillips. Dose-escalation with CHARTWEL (Continuous Hyperfractionated Accelerated Radiotherapy WeekEnd Less) Combined with Neo-adjuvant Chemotherapy in the Treatment of Locally Advanced Non-small Cell Lung Cancer. Clinical oncology, october 2002;14( 5): 352-360. 